


About IJMA
International Journal of Medical Arts is the Official Scientific Journal
of the Damietta Faculty of Medicine, Al-Azhar University, Egypt
It is an International, Open Access, Double-blind, Peer-reviewed,
monthly-published (starting January 2022) Journal
The First Issue was published in July 2019
Published under the following license: Creative Commons
Attribution-ShareAlike 4.0 International Public License (CC BY-SA
4.0).
The Egyptian Knowledge Bank hosts the web site and supports
IJMA follows the regulations of the International Committee of
Medical Journal Editors
IJMA is a member of the International Society of Managing and
Technical Editors
IJMA is indexed in the "Directory of Open Access Journals"
[Indexed on 15 January 2021], Index Copernicus and J-Gate [29-6-
IJM21].
IJMA Listed in
"Publons", "Academic resource index [ResearchBib]", "Electronics journal
Jibrary", "Eurasian Scientific Journal Index", World Catalogue of Scientific
WorldCat and "Citefactor"




Available online at Journal Website
https://ijma.journals.ekb.eg/
Main Subject [Gynecology and Obstetrics]

Original Article

\title{
Evaluation of the Calculated Risk of Malignancy Index as a Predictor of the Nature of Adnexal Masses
}

\author{
Taher Mohamed Mostafa Hassan ${ }^{*[1]}$; Ahmed Ali Ali Assem ${ }^{[2]}$; Wafik Ibrahim ${ }^{[3]}$ \\ ${ }^{1}$ Department of Obstetrics and Gynecology, Faculty of Medicine, Al-Azhar University, Egypt \\ ${ }^{2}$ Department of Clinical Pathology, Faculty of Medicine, Al-Azhar University, Egypt. \\ ${ }^{3}$ Department of Radiology, Faculty of Medicine, Al-Azhar University, Egypt.
}

\begin{tabular}{|c|c|}
\hline \multicolumn{2}{|c|}{ Article information } \\
\hline Submitted: & $29-11-2021$ \\
\hline Accepted: & $16-01-2022$ \\
\hline \multicolumn{2}{|c|}{ DOI: 10.21608/ijma.2022.214364 } \\
\hline \multicolumn{2}{|c|}{$\begin{array}{l}* \text { Corresponding author } \\
\text { Email: taherelbarbari@gmail.com }\end{array}$} \\
\hline \multicolumn{2}{|c|}{$\begin{array}{l}\text { Citation: Hassan TMM, Assem AAA, } \\
\text { Ibrahim W. Evaluation of the Calculated } \\
\text { Risk of Malignancy Index as a Predictor of } \\
\text { the Nature of Adnexal Masses. IJMA } 2022 \\
\text { Jan; } 4 \text { [1]: 2073-2081 [DOI: } 10.21608 / \text { ijma. } \\
\text { 2022.214364]. }\end{array}$} \\
\hline
\end{tabular}

\section{ABSTRACT}

Background: Adnexal masses are common presentation among gynecological practice. Differentiation of benign than malignant lesions is of utmost importance for treatment plan. The gold standard other than histopathology did not determined yet.

The aim of the work: The current work aimed to measure the predictive power of the preoperative risk of malignancy index [RMI] to discriminate between benign and malignant adnexal masses.

Patients and Methods: This study included 80 patients, presented with adnexal masses/ovarian cysts. They were managed by surgery, during the period from May 2015 to November 2017. We collected the following data: age, gravidity, menopause status, parity, cancer antigen 125 [CA125] levels and ultrasound results. RMI was calculated according to Tingulstad' model. Postoperatively, histopathology results were documented for every patient and used as the gold standard diagnostic modality to measure predictive power of RMI and CA125.

Results: Malignant lesions were documented in $27.5 \%$, while $72.5 \%$ were benign. The benign tumors were significantly associated with younger age than malignant lesions [27.88 \pm 7.68 versus 41.05 \pm 11.81$]$. The postmenopausal women percentages were significantly higher among malignant than benign ovarian lesions $[45.5 \%$ vs. $1.7 \%$, respectively, $\mathrm{p}<$ 0.001]. All ultrasound parameters of RMI were significantly different in malignant than benign masses. The optimal cutoff points of RMI and CA125 were 90.6 and 20.0 respectively. At such points, RMI had 90.6 sensitivity. However, specificity, positive predictive value, negative predictive values were $68.2 \%, 75.9 \%, 51.7 \%$ and $86.3 \%$, respectively.

Conclusion: RMI represented a significant indicator in preoperative assessment of adnexal mass, and was valuable to refer patients to oncology centers, and recommended for screening purposes.

Keywords: Adnexal mass; Risk of Malignancy Index; CA125; Ovarian Cancer; Ultrasonography.

This is an open-access article registered under the Creative Commons, ShareAlike 4.0 International license [CC BY-SA 4.0] [https://creativecommons.org/licenses/by-sa/4.0/legalcode.

\section{INTRODUCTION}

Adnexal masses are common among gynecological practice and may affect females at any age. Ovarian malignancy is the commonest second gynecological malignancy and the first lethal gynecologic malignancy and fifth commonest cause of death among women [1]. It usually discovered at advanced stage and this could explain the high mortality rate. They may be discovered accidentally while evaluating women of other pelvic complaints or 
even in asymptomatic patients. Symptoms when present are non-specific and could include abdominal fullness, nausea, early satiety, irregular menses or vaginal bleeding, fatigue, change in bowel habits, urinary manifestations, back pain, dyspareunia, loss of weight, or manifestation of metastasis in advanced stages [2-4].

Because the patient usually complains of abdominal symptoms, pelvic examination may be escaped and tumor diagnosis may be missed. Benign diseases affecting the reproductive tract, as pelvic inflammatory disease [PIDs], endometriosis, and pedunculated leiomyoma, can simulate malignant ovarian tumors. Nongynecologic causes of an adnexal mass, such as inflammatory disease or neoplastic colonic mass or even a pelvic kidney can simulate ovarian cancer ${ }^{[5,6]}$.

A careful history taking and pelvic examination is an important step for the diagnosis. However, the diagnostic accuracy of pelvic examination varied in different series between $50 \%$ and $90 \%$. It is affected by several variables including the experience of the gynecologist, the type of the patient and the characteristics of the mass. Several factors may hinder the diagnosis, even for an experienced gynecologist: virginity, obesity, associated pregnancy, ascites and pelvic tenderness ${ }^{[7-11]}$.

In preoperative evaluation and prediction of the adnexal masses benign or malignant characters is important and a precise diagnosis is required for choosing appropriate management method. Many women who had ovarian cancer are presented in late stages. The reason is that the lack of effective screening methods to detect the disease at early stages ${ }^{[12}$, 13].

In case of high values of CA125, assessment of CA125 and then ultrasound is considered the most efficient screening method ${ }^{[14]}$. The survival rate is related to the stage of the disease at the diagnosis. In patients diagnosed with advanced stage III-IV ovarian cancer, the 5-year survival rate is about $30 \%$, whereas in those diagnosed at an early stage the 5-year survival rate is about $90 \%$ [15-17]. Therefore, it seems worthwhile to diagnose ovarian cancer at an early stage ${ }^{[18]}$.

The number of women having adnexal masses has increased markedly due to the extensive use of ultrasonography, and as a result of the low malignancy possibility of these masses, a lot of ultrasound signs were defined to follow up these patients without the need for surgical interventions due to low malignancy potential. It is estimated that $5-10 \%$ of women in The US will submitted to a surgical intervention for a suspected ovarian cancer during their lifetime, and $13-21 \%$ of these women will be found to have a malignant ovarian neoplasm ${ }^{[6,19]}$.

In many conditions diagnosis is done after histopathologic evaluation or throughout the surgery. Unnecessary surgical procedures results from inadequate diagnostic tools preoperatively. Different laboratory markers, imagination methods and clinical parameters were presented for identifying malignancy potential of an adnexal mass ${ }^{[16]}$.

\section{THE AIM OF THE WORK}

The current work aimed to measure the accuracy of the preoperative risk of malignancy index [RMI] to differentiate between benign and malignant adnexal masses.

\section{PATIENTS AND METHODS}

\section{Patients}

The present study was a prospective study, conducted at the Department of Obstetrics \& Gynecology, Bab-Elshaarea [Sayed Galal] University Hospital, from May 2015 to November 2017. The study included 80 patients who had a preliminary diagnosis of an adnexal mass, which was detected clinically and confirmed sonographically to be an adnexal mass. The patients were included, regardless the patients' complaint, age or parity, and scheduled for surgical intervention. Postmenopausal status was defined as more than one year of amenorrhea in women over the age of 45 years or an age of more than 50 years in women who had undergone a hysterectomy. All other women were considered premenopausal. 


\section{Material and Methods}

All patients, after signing an informed consent were subjected to full history, systemic clinical examination and patients with query malignant adnexal masses had further evaluation, ordered according to the view of the treating physician. These data were not incorporated in the study. However, the laboratory investigations included complete blood count, liver and kidney functions, random blood sugar and urinalysis. In addition, quantitative assessment of serum CA 125 levels were measured for all participants.

An abdomino-pelvic ultrasonographic examination had been carried out to asses features suggestive manifestations of malignancy [e.g., multilocularity [more than bilocular], presence of solid areas, bilaterality, presence of ascites, and extraovarian tumors/evidence of metastases].

All surgically removed specimens were examined histopathologically in the Department of Pathology, Sayed Galal University Hospital to confirm their nature. The histopathological diagnosis was considered the gold standard to define the outcome, being classified as; benign or malignant according to FIGO classification.

\section{Risk of malignancy index}

The "risk of malignancy index" calculated for the ovarian cancer prediction in the present study depends on Tingulstad et al. ${ }^{[20]}$; Bailey et al. ${ }^{[21]}$. To differentiate benign than malignant adnexal mass, RMI at 230 is a cutoff point to discriminate between them ${ }^{[22]}$.

With attribution of values, 1 for premenopausal status and 3 for postmenopausal status [M], ultrasound score [US] being 0,1 , or 3 according to a morphology index and the absolute values of CA 125 serum levels in $\mathrm{U} / \mathrm{ml}$, RMI was calculated as follows: $\mathrm{RMI}=$ US x M x CA 125 as described by Tingulstad et al. ${ }^{[20]}$. Malignancy is predicted if ultrasound score [U] was 3, CA125 values $\geq 35$, and postmenopausal or $\mathrm{RMI} \geq 230$.

\section{Measurement of tumor markers}

CA125 measurement was performed in the Clinical Pathology Department in Bab elshaarea Hospital, after obtaining a venous blood sample from the selected patients, using solid phase enzyme-linked immunosorbent assay [American Laboratory Products Company, Windham, NH, USA]. In order to avoid bias at the time of performing US evaluation, the results of the serum CA125 were reviewed only after the US was performed.

\section{Ultrasonographic Evaluation}

It was done using a Voluson E-6 machine [GE Health Care USA] with multifrequency trans-abdominal and trans-vaginal volumetric probes, where Patients with pelvic masses larger than $10 \mathrm{~cm}$ had in addition a trans-abdominal ultrasound. The used probes were set at various frequencies. For example, the transvaginal route, with 4-9 $\mathrm{MHz}$ frequency [using an average $6.5 \mathrm{MHz}$ intracavitary probe]. However, transabdominal route used with 2-6 $\mathrm{MHz}$ frequency [using an average $3.5 \mathrm{MHz}$ convex probe]. Identical fixed pre-installed power Doppler ultrasound settings were used: frequency, 6-9 ['normal'] $\mathrm{MHz}$; pulse repetition frequency, $0.6 \mathrm{kHz}$; gain, -4.0 ; wall motion filter, 'low 1' [40 Hz].

\section{Ethical considerations}

The study protocol had been approved by the local ethics committee of Faculty of Medicine, Al-Azhar University. All women signed an informed consent to participate in the study.

\section{Statistical analysis}

Analysis of data was done by IBM computer using SPSS Inc., [Statistical Program for Social Science Inc.,] Chicago, IL, USA, version 12.02 as follows: Qualitative data were expressed as frequency and percentage. Chi-square test [Fisher's exact test] was used to examine the relation between qualitative variables. Numerical data were expressed and presented in terms of range, mean, standard deviation and percentages. "Mann-Whitney test" was used for quantitative data analysis to compare between the two groups. Correlation between variables 
was tested by Spearman-rho. The "Receiver Operating Characteristic" [ROC] curve was used for prediction of cut off values. Level of significance [probability " $\mathrm{P}$ " value] is evaluated, where $P$ value $<0.05$ is of significant value.

\section{RESULTS}

Pathology reports of the 80 patients revealed that, 22 [27.5\%] were malignant and 58 [72.5\%] were benign. The distribution of benign and malignant masses was presented in table [1]. The mean age of patients with benign disease was $27.88 \pm 7.68$, while it was $41.05 \pm 11.8$ years in those with malignant disease, with significant association between younger age and benign tumors $[p<0.001]$. In addition, benign tumors were associated with primiparity and low parity [P1 and P2], while malignant masses were associated with $\mathrm{P} 2$ and $\mathrm{P} 3[\mathrm{P}=0.004]$ [Table 2].

Ultrasound scoring and features, menopausal status are shown in figures [1], [2] respectively. Malignant masses were associated with multilocular, solid areas, bilaterality and ascites. In addition, malignant masses were significantly higher among postmenopausal women.

The mean serum level of CA125 was significantly higher among women with malignant masses when compared with women who had a benign adnexal mass [mean values were $113.86 \mathrm{IU} / \mathrm{mL}$ versus $16.83 \mathrm{IU} / \mathrm{mL}$, respectively and $\mathrm{p}<0.05]$.

The RMI at the cut-off level of 90.60 had a sensitivity $68.2 \%$, specificity $75.9 \%$, PPV $51.7 \%$, NPV $86.3 \%$. The comparative diagnostic performance of RMI score of our study is shown in Table [3]. However, CA-125 cut-off > 20.0IU/ml, had sensitivity of $77.3 \%$, specificity of $69.0 \%$, positive predictive value of $48.6 \%$ and negative predictive value of $88.9 \%$ [Table 3 and figures 3].

Table [1]: The histopathology results of benign and malignant cases

\begin{tabular}{|c|c|c|c|}
\hline & & No. & $\%$ \\
\hline \multirow[t]{10}{*}{ Benign tumors [58 patients] } & Cystadeno-fibroma & 1 & 1.72 \\
\hline & Endometrioma & 13 & 22.41 \\
\hline & Fibroma & 1 & 1.72 \\
\hline & Hemorrhagic corpus leuteum & 2 & 3.45 \\
\hline & Mature teratoma & 6 & 10.34 \\
\hline & Mucinous cystadenoma & 2 & 3.45 \\
\hline & Myoma & 6 & 10.34 \\
\hline & Serous cystadenoma & 2 & 3.45 \\
\hline & Simple serous cyst & 5 & 8.62 \\
\hline & Tubo-ovarian abscess & 20 & 34.48 \\
\hline \multirow[t]{5}{*}{ Malignant tumors [22 patients] } & Clear cell car. & 1 & 4.55 \\
\hline & Cystadenocarcinoma & 11 & 50.00 \\
\hline & Dysgerminoma & 3 & 13.64 \\
\hline & Granulosa cell tumor & 2 & 9.09 \\
\hline & Krukenberg tumor & 5 & 22.73 \\
\hline
\end{tabular}

Table [2]: The distribution of benign and malignant cases by age and parity

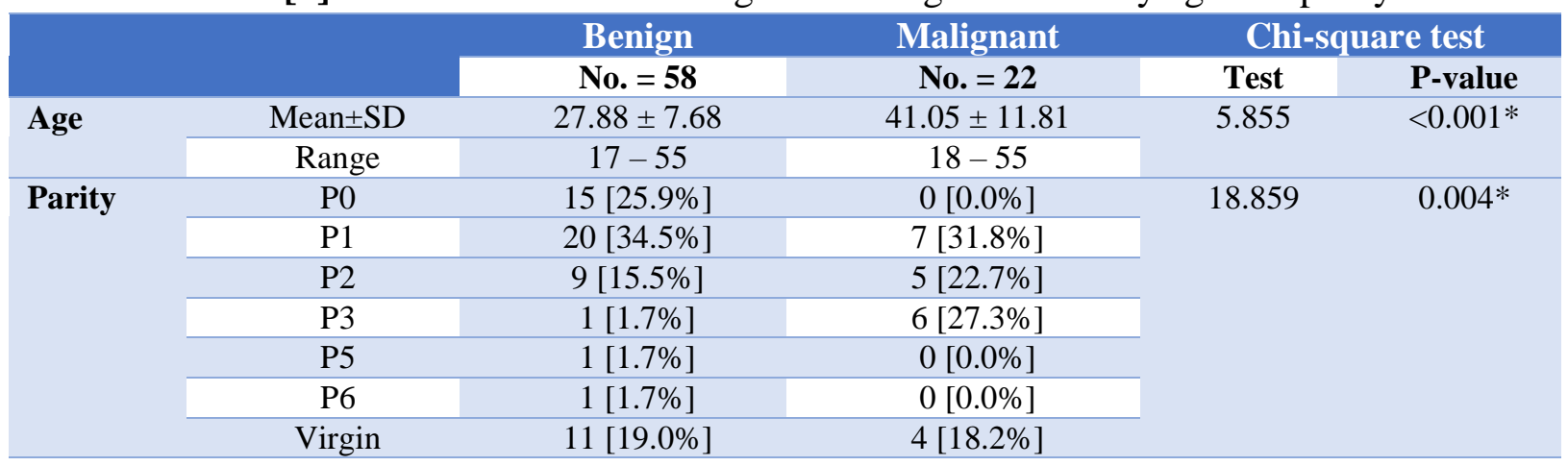




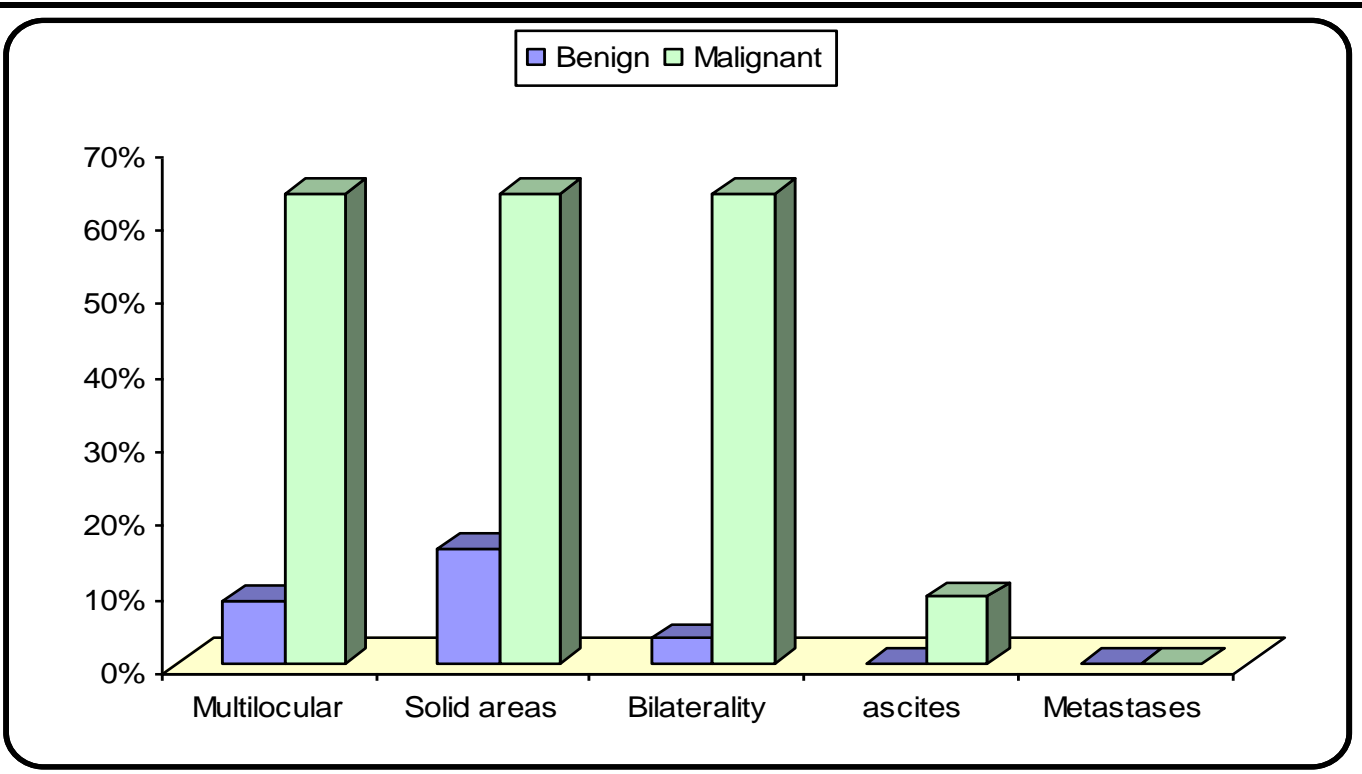

Figure [1]: Distribution of ovarian masses in patients according to ultrasound finding

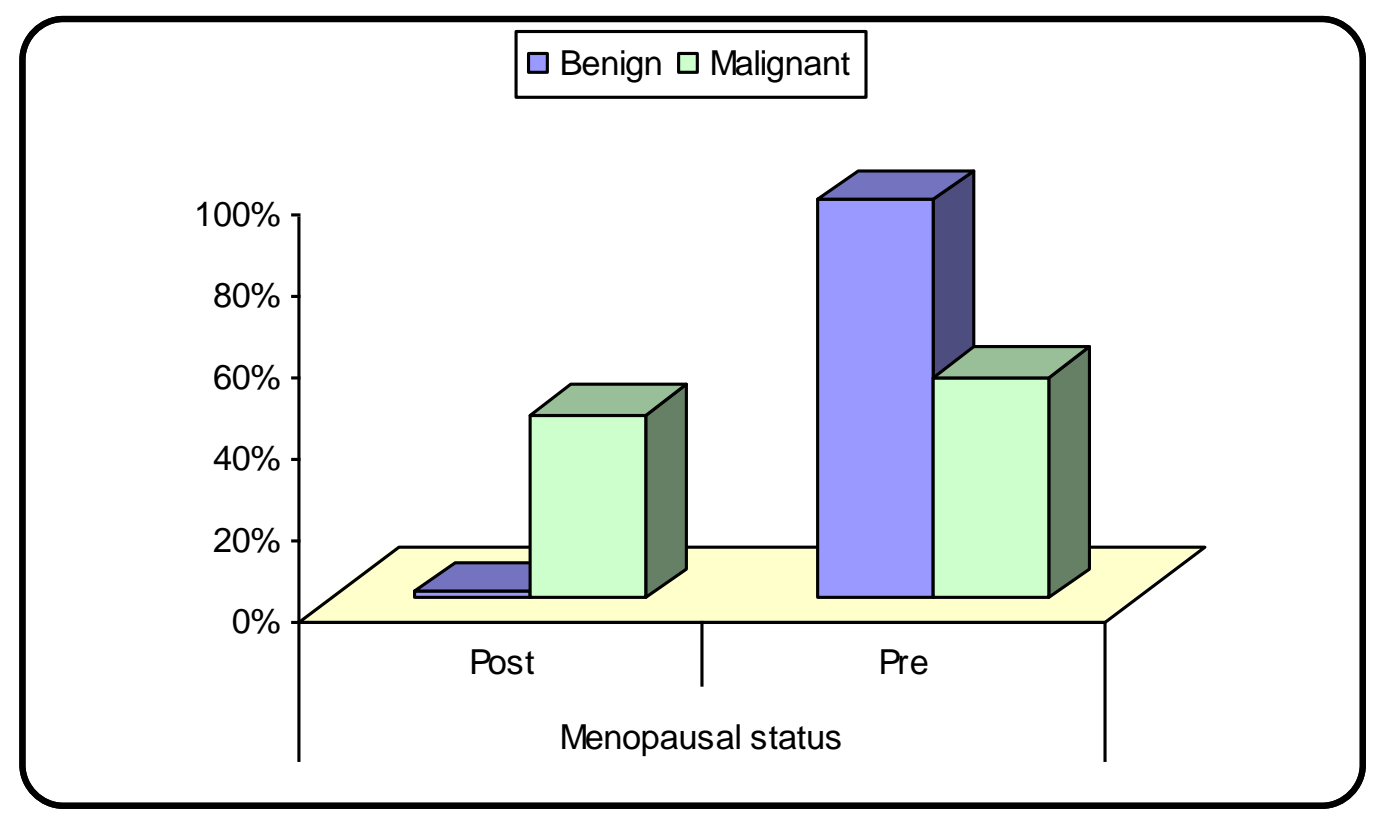

Figure [2]: Distribution of ovarian masses in patients, according to their menopausal status

Table [3]: Sensitivity, specificity, positive predictive value [PPV] and negative predictive value [NPV] for RMI and CA-125

\begin{tabular}{|c|c|c|c|c|c|c|}
\hline Variables & $\begin{array}{c}\text { Cut off } \\
\text { point }\end{array}$ & AUC & Sensitivity & Specificity & + PV & -PV \\
\hline RMI & $>90.6$ & 0.721 & 68.2 & 75.9 & 51.7 & 86.3 \\
\hline CA-125 & $>20.0$ & 0.752 & 77.3 & 69.0 & 48.6 & 88.9 \\
\hline
\end{tabular}



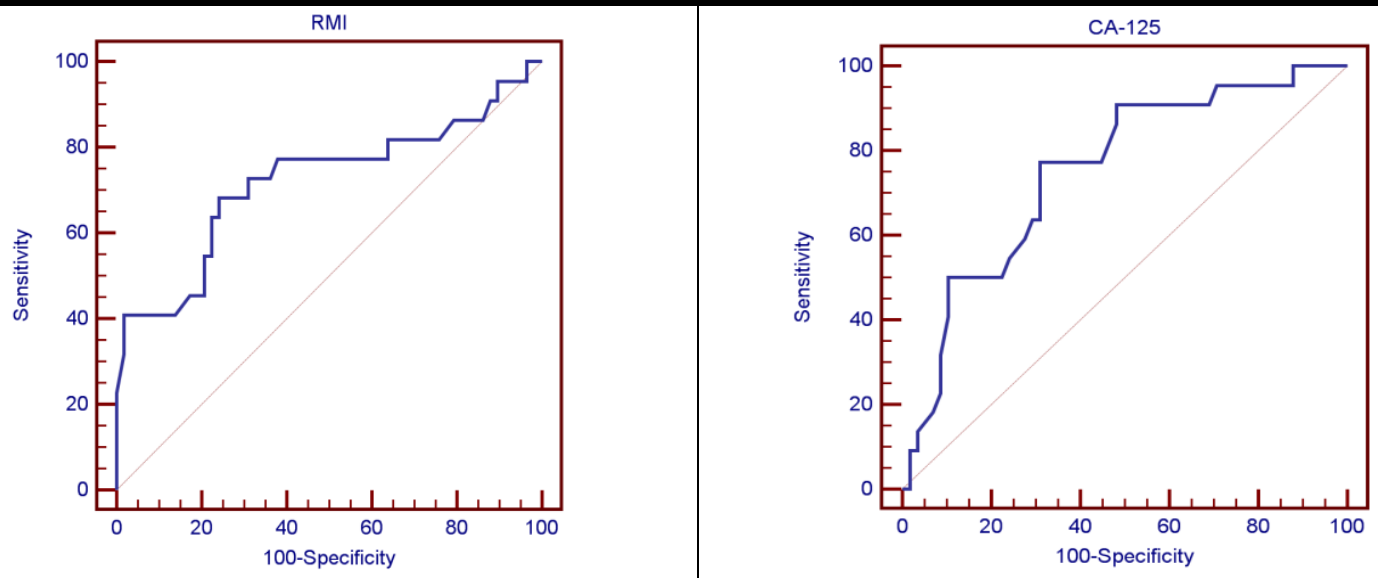

Figure [3]: The Receiver operating characteristic curves of RMI and CA125 level

\section{DISCUSSION}

Ovarian malignancy is one of the leading causes of cancer deaths among women ${ }^{[23]}$. Prognosis would dramatically improve if ovarian carcinoma might be diagnosed early, and therefore the got to do so is greatest for serous ovarian carcinoma, which is never diagnosed at stage Ia. Asymptomatic women would be screened to reach this, as a result of the late appearance of the symptoms. Assays measuring tumor markers in serum or other body fluids have the advantage of being noninvasive, simple to perform and relatively cheap. Since one among 2500 postmenopausal women is likely to develop ovarian carcinoma in the USA, an acceptable screening assay would require a sensitivity of $75 \%$ and specificity of about $99.7 \%$ to obtain minimally tolerable positive predictive value of $10 \%$ for the detection of ovarian carcinoma ${ }^{[24-26]}$. The main tools we used were clinical manifestations, estimation of serum CA125 and calculation of the RMI for the study population, and applying different ultrasound features on the adnexal masses in these cases, but a single method which can accurately predict ovarian malignancy is still unavailable. A scoring system predicting ovarian cancer [differentiate between benign and malignant lesions] can lead to better preoperative preparation and surgical intervention, in a suitable center.

This study was carried out on 80 women with ovarian mass. Of them, 58 [72.5\%] had a benign ovarian lesion, while 22 [27.5\%] had a malignant lesion. Malignant lesions were significantly higher among post-menopausal women. These results are in line with Dora $\boldsymbol{e t}$ al. [27], who reported that, post-menopausal women represented $81.6 \%$ of malignant, compared to $18.4 \%$ of benign lesions. Rai et al. ${ }^{[28]}$ reported that, benign lesions represented $82.4 \%$ of their sample of 127 adnexal masses. Furthermore, Al Musalhi et al. ${ }^{\text {[29] }}$ reported that, $77.5 \%$ of ovarian specimens were benign and $22.5 \%$ were malignant.

Results of the current study revealed that, the ultrasound manifestations have a high correlation to histopathology, regarding multilocularity, solid masses, bi-laterality and ascites. Thus, absence of these manifestations is an excellent tool for excluding malignancy. In addition, serum CA125 and RMI were significantly higher among malignant than benign cases. CA125 was useful for differentiation between benign and malignant adnexal masses, and at a cutoff value of " 35 $\mathrm{u} / \mathrm{ml}$ ", provides sensitivity of $77.3 \%$, specificity of $69 \%$, PPV of $48.6 \%$ and NPV of $88.9 \%$. Raising the cut off value of CA125 improved the specificity with detrimental effect on the sensitivity. The cutoff value of RMI $>230$ provides sensitivity of $68.2 \%$, specificity of $75.9 \%$, PPV of $51.7 \%$ and NPV of $86.3 \%$, with high correlation with histopathology and sonographic results. Receiver operator characteristics [ROC] curves were analysis for the CA125 serum level and RMI values accuracy, in prediction of malignancy in the adnexal masses, in correlation to resultant pathology revealed that area under the curves [AUC] for both, were 0.752 and 0.721 respectively. These reflected discriminatory potentials, at cut-off values of $20 \mathrm{u} / \mathrm{ml}$ for serum level of CA125 and 90.6 for RMI value. 
Tingulstad et al. ${ }^{[20]}$ found a sensitivity of $76 \%$ and specificity of $82 \%$ in 1996 for RMI. In a later study in 1999 Tingulstad et al. ${ }^{[30]}$ reported a sensitivity of $74 \%$ and a specificity of $91 \%$ respectively. In an extensive retrospective analysis, Bailey et al. ${ }^{[21]}$ confirmed the effectiveness of the RMI to identify ovarian malignancy presenting at cancer units. Al Musalhi et al. ${ }^{[29]}$ concluded that, CA-125 and HE4, as well as ROMA and RMI values, are useful indicators to discriminate benign from malignant ovarian tumors. In addition, AlAsadi et al. ${ }^{[31]}$ concluded that, the RMI is a reliable, simple, sensitive, and practical indicator for pre-operative differentiation between benign and malignant adnexal masses. The use of RMI can facilitate the proper selection of patients for appropriate treatment or timely referral to specialized oncology centers. Their results are in line with the current work, as malignant lesions were associated with older age $[58.4 \pm 8.4$ vs $36.9 \pm 10.7$ years], post-menopausal $[76.2 \%$ vs $6.2 \%]$, high ultrasound score $[95.2 \%$ vs $25.0 \%]$, higher CA-125 [914.1 \pm 727.9 vs $44.8 \pm 30.1 \mathrm{IU} / \mathrm{ml}]$ and higher $\mathrm{RMI}$ [6490.6 \pm 63.0 vs $42.6 \pm 30.1]$. RMI $\geq 200$ had a sensitivity of $100.0 \%$, specificity of $92.6 \%$, PPV of $87.5 \%$ and NPV of $100.0 \%$, while CA$125 \geq 35 \mathrm{IU} / \mathrm{ml}$ had sensitivity of $100.0 \%$, specificity of $80.0 \%$, PPV of $65.7 \%$ and NPV of $100.0 \%$.

RMI was reported in other studies to be a reliable indicator in discrimination between benign and malignant pelvic mass [32-33]. However, its clinical use in medical community depends on clinician's use. To maximize its use, programs to advocate its values to clinicians are mandatory ${ }^{[34]}$. On the other side, previous studies reported on the inadequacy of RMI in the detection of ovarian tumors where non-epithelial cancer and borderline tumors are prevalent [35-36]. However, the same researchers suggest further validation of their study results due to small number of cases.

The main advantages of RMI are its simplicity and clinical applicability in nonspecialized gynecological departments ${ }^{[36]}$. It also provides a base for referral to specialized centers for effective surgical interventions ${ }^{[37]}$.

Finally, results of the current study are in line with Isgandarova et $\boldsymbol{a l} .{ }^{[38]}$ who reported that, mean age and CA-125 levels, and ultrasonography scores were higher in malignant cases. RMI scores were higher in the malignant than benign group [1728.14 \pm 325.3 vs. $36.27 \pm 31.01, \mathrm{p}<0.001]$. The discriminative value of RMI to predict malignancy revealed that, AUC was 0.930 with a sensitivity of $95 \%$, the specificity of $75 \%$, the PPV of $79.1 \%$ and VPV of $93.7 \%$ with a cut-off value of $>53.2$. However, these values are higher than the current one and that could be attributed to different cutoff value. Confirming this explanation, the same authors reported that, when calculated the predictive indicators of RMI at cutoff value of 200 [as many previous studies], the sensitivity was $60.0 \%$, specificity $100.0 \%$, PPV of $100.0 \%$ and NPV of $71.4 \%$.

Conclusion: Irrespective of the fact that, histopathological examination of the adnexal lesion is the gold standard for diagnosis or exclusion of malignancy, RMI in addition to ultrasound are reasonably accurate, helpful and non-invasive tools to discriminate between benign and malignant adnexal lesions. We recommend the use of RMI as a screening tool, and it may be used with other non-invasive modalities such as ultrasound.

Financial and non-financial activities and relationships of interest: None.

\section{REFERENCES}

1. Siegel RL, Miller KD, Jemal A. Cancer statistics, 2020. CA Cancer J Clin. 2020 Jan;70[1]:7-30. DOI: $10.3322 /$ caac. 21590.

2. Smith CG. A Resident's Perspective of Ovarian Cancer. Diagnostics [Basel]. 2017 Apr 27;7[2]:24. DOI: 10.3390/diagnostics7020024.

3. Lheureux S, Gourley C, Vergote I, Oza AM. Epithelial ovarian cancer. Lancet. 2019;393[10177]:1240-1253. DOI: 10.1016/S0140-6736[18]32552-2.

4. Renjen PN, Chaudhari DM, Shilpi US, Zutshi D, Ahmad K. Paraneoplastic Cerebellar Degeneration Associated With Ovarian Adenocarcinoma: A Case Report and Review of Literature. Ann Indian Acad Neurol. 2018 
Oct-Dec;21[4]:311-314. DOI: 10.4103/ aian.AIAN_411_17.

5. Di Legge A, Pollastri P, Mancari R, Ludovisi M, Mascilini F, Franchi D, et al. Clinical and ultrasound characteristics of surgically removed adnexal lesions with largest diameter $\leq 2.5 \mathrm{~cm}$ : a pictorial essay. Ultrasound Obstet Gynecol. 2017 Nov;50[5]:648-656. DOI: 10.1002/uog.17392.

6. Terzic M, Dotlic J, Bila J, Pilic I, Nikolic B, Kocijancic D, et al. Utilization of ultrasound as a diagnostic tool in the preoperative assessment of patients with adnexal masses. $\mathrm{J}$ BUON. 2015 May-Jun;20[3]:862-9. PMID: 26214641.

7. Blamble $\mathrm{T}$, Dickerson L. Recognizing and treating endometriosis. JAAPA. 2021 Jun $1 ; 34[6]: 14-19$.

DOI:

10.1097/01.JAA.0000750940.47126.58.

8. Ball E, Khan KS. Recent advances in understanding and managing chronic pelvic pain in women with special consideration to endometriosis. F1000Res. 2020 Feb 4;9: F1000 Faculty Rev-83. DOI: 10.12688/ f1000research.20750.1.

9. Freytag D, Mettler L, Maass N, Günther V, Alkatout I. Uterine anomalies and endometriosis. Minerva Med. 2020; 111[1]:3349. DOI: 10.23736/S0026-4806.19. 06341-9.

10. Chapron C, Marcellin L, Borghese B, Santulli P. Rethinking mechanisms, diagnosis and management of endometriosis. Nat Rev Endocrinol. 2019; 15[11]:666-682. DOI: 10.1038/s41574-019-0245-z.

11. Falcone T, Flyckt R. Clinical Management of Endometriosis. Obstet Gynecol. 2018;131[3]:557-571. DOI: 10.1097/AOG.0000000000002469.

12. Cagino $\mathrm{K}, \mathrm{Li} \mathrm{X}$, Thomas $\mathrm{C}$, Delgado $\mathrm{D}$, Christos P, Acholonu U Jr. Surgical Management of Adnexal Masses in Pregnancy: A Systematic Review and Meta-analysis. J Minim Invasive Gynecol. 2021 Jun;28[6]:1171-1182.e2.

DOI: 10.1016/j.jmig.2021. 01.020.

13. Vázquez-Manjarrez SE, Rico-Rodriguez OC, Guzman-Martinez N, Espinoza-Cruz V, LaraNuñez D. Imaging and diagnostic approach of the adnexal mass: what the oncologist should know. Chin Clin Oncol. 2020 Oct;9[5]:69. DOI: $10.21037 / \mathrm{cco}-20-37$.

14. Salvador S, Scott S, Glanc P, Eiriksson L, Jang
JH, Sebastianelli A, Dean E. Guideline No. 403: Initial Investigation and Management of Adnexal Masses. J Obstet Gynaecol Can. 2020 Aug;42 [8]: 1021-1029.e3. DOI: 10.1016/j.jogc.2019.08.044.

15. Siddiqui MK, Tyczynski J, Pahwa A, Fernandes AW. Objective response rate is a possible surrogate endpoint for survival in patients with advanced, recurrent ovarian cancer. Gynecol Oncol. 2017; 146[1]:44-51. DOI: 10.1016/j.ygyno.2017.03.515.

16. Huang Y, Ming X, Li B, Li Z. Histological Characteristics and Early-Stage Diagnosis Are Associated With Better Survival in Young Patients With Epithelial Ovarian Cancer: A Retrospective Analysis Based on Surveillance Epidemiology and End Results Database. Front Oncol. 2020 Dec 23;10: 595789. DOI: $10.3389 /$ fonc. 2020.595789 .

17. Villanueva C, Chang J, Ziogas A, Bristow RE, Vieira VM. Ovarian cancer in California: Guideline adherence, survival, and the impact of geographic location, 1996-2014. Cancer Epidemiol. 2020 Dec; 69:101825. DOI: 10.1016/j.canep.2020.101825.

18. Bast RC Jr, Lu Z, Han CY, Lu KH, Anderson KS, Drescher CW, Skates SJ. Biomarkers and Strategies for Early Detection of Ovarian Cancer. Cancer Epidemiol Biomarkers Prev. 2020 Dec;29[12]:2504-2512. DOI: 10.1158/ 1055-9965.EPI-20-1057.

19. Rocha RM, Barcelos IDES. Practical Recommendations for the Management of Benign Adnexal Masses. Rev Bras Ginecol Obstet. 2020 Sep;42[9]:569-576. English. DOI: $10.1055 / \mathrm{s}-0040-1714049$.

20. Tingulstad S, Hagen B, Skjeldestad FE, Onsrud M, Kiserud T, Halvorsen T, Nustad K. Evaluation of a risk of malignancy index based on serum CA125, ultrasound findings and menopausal status in the pre-operative diagnosis of pelvic masses. $\mathrm{Br} \mathrm{J}$ Obstet Gynaecol. 1996 Aug;103[8]:826-31. DOI: 10.1111/j. 1471-0528.1996.tb09882.x.

21. Bailey J, Tailor A, Naik R, Lopes A, Godfrey K, Hatem HM, Monaghan J. Risk of malignancy index for referral of ovarian cancer cases to a tertiary center: does it identify the correct cases? Int J Gynecol Cancer. 2006 Jan-Feb;16 Suppl 1:30-4. DOI: 10.1111/j.1525-1438.2006.00468.x.

22. Amen NS, Jameel BZ, Najm NA. Evaluation of the 'Ovarian Crescent Sign'in the Preoperative 
Determination of the Nature of Adnexal Masses. Iraqi Postgraduate Med J. 2014; 13 [2]: 328-335.

23. Torre LA, Trabert B, DeSantis CE, Miller KD, Samimi G, Runowicz CD, Gaudet MM, Jemal A, Siegel RL. Ovarian cancer statistics, 2018. CA Cancer J Clin. 2018 Jul;68[4]:284-296. DOI: $10.3322 /$ caac.21456.

24. Abdalla N, Piorkowski R, Bachanek M, Stanirowski P, Cendrowski K, Sawicki W. Does the Risk of Ovarian Malignancy Algorithm Provide Better Diagnostic Performance Than HE4 and CA125 in the Presurgical Differentiation of Adnexal Tumors in Polish Women? Dis Markers. 2018 Apr 10;2018: $\quad 5289804 . \quad$ DOI: $10.1155 / 2018 / 5289804$.

25. Zhang Q, Wang CR, Yu JP, Ma Q, Xu WW. The Establishment of an HE4-CLIA Method and the Combined Analysis of HE4 and CA125 in Ovarian Cancer. J Clin Lab Anal. 2016 Sep;30[5]:709-18. DOI: $10.1002 /$ jcla.21926.

26. Chudecka-Głaz A, Cymbaluk-Płoska A, Jastrzębska J, Menkiszak J. Can ROMA algorithm stratify ovarian tumor patients better when being based on specific age ranges instead of the premenopausal and postmenopausal status? Tumour Biol. 2016; 37[7]:8879-87. DOI: 10.1007/s13277-0154733-z.

27. Dora SK, Dandapat AB, Pande B, Hota JP. A prospective study to evaluate the risk malignancy index and its diagnostic implication in patients with suspected ovarian mass. J Ovarian Res. 2017 Aug 14;10[1]:55. DOI: 10.1186/s13048-017-0351-2.

28. Rai R, Bhutia PC, Tshomo U. Clinicopathological profile of adnexal masses presenting to a tertiary-care hospital in Bhutan. South Asian J Cancer. 2019 Jul-Sep;8[3]:168172. DOI: 10.4103/sajc.sajc_303_18.

29. Al Musalhi K, Al Kindi M, Al Aisary F, Ramadhan F, Al Rawahi T, Al Hatali K, MulaAbed WA. Evaluation of HE4, CA-125, Risk of Ovarian Malignancy Algorithm [ROMA] and Risk of Malignancy Index [RMI] in the Preoperative Assessment of Patients with Adnexal Mass. Oman Med J. 2016 Sep;31[5]:336-44. DOI: 10.5001/omj.2016.68.

30. Tingulstad S, Hagen B, Skjeldestad FE, Halvorsen T, Nustad K, Onsrud M. The riskof-malignancy index to evaluate potential ovarian cancers in local hospitals. Obstet Gynecol. 1999 Mar;93[3]:448-52. PMID: 10074998.

31. Al-Asadi JN, Al-Maliki SK, Al-Dahhhan F, AlNaama L, Suood F. The accuracy of risk malignancy index in prediction of malignancy in women with adnexal mass in Basrah, Iraq. Niger J Clin Pract. 2018; 21[10]:1254-1259. DOI: $10.4103 /$ njcp.njcp_424_16.

32. Moolthiya W, Yuenyao P. The risk of malignancy index [RMI] in diagnosis of ovarian malignancy. Asian Pac J Cancer Prev. 2009;10[5]:865-8. PMID: 20162854.

33. Akturk E, Karaca RE, Alanbay I, Dede M, Karaşahin E, Yenen MC, Başer I. Comparison of four malignancy risk indices in the detection of malignant ovarian masses. J Gynecol Oncol. 2011 Sep;22[3]:177-82. DOI: 10.3802/jgo.2011.22.3.177.

34. Moore RG, Bast RC Jr. How do you distinguish a malignant pelvic mass from a benign pelvic mass? Imaging, biomarkers, or none of the above. J Clin Oncol. 2007 Sep 20;25[27]:4159-61. $\quad$ DOI: 10. 1200/JCO.2007.11.9594.

35. Meray $\mathrm{O}$, Türkçüoğlu I, Meydanlı MM, Kafkasl1 A. Risk of malignancy index is not sensitive in detecting non-epithelial ovarian cancer and borderline ovarian tumor. J Turk Ger Gynecol Assoc. 2010 Mar 1;11[1]:22-6.

36. Yazbek J, Aslam N, Tailor A, Hillaby K, Raju KS, Jurkovic D. A comparative study of the risk of malignancy index and the ovarian crescent sign for the diagnosis of invasive ovarian cancer. Ultrasound Obstet Gynecol. 2006;28[3]:320-4. DOI: 10.1002/uog.2842.

37. Karimi-Zarchi M, Mojaver SP, Rouhi M, Hekmatimoghaddam SH, Moghaddam RN, Yazdian-Anari P, Teimoori S. Diagnostic Value of the Risk of Malignancy Index [RMI] for Detection of Pelvic Malignancies Compared with Pathology. Electron Physician. 2015;7[7]:1505-10. DOI: 10.19082/1505.

38. Isgandarova A, Yumru AE, Karatas S, Cakmak BD, Dundar B, Turker UA. The Comparison of Pelvic Mass Score and Risk of Malignancy Index-3 in Discrimination of Benign and Malignant Adnexal Masses. Sisli Etfal Hastan Tip Bul. 2020;54[4]:490-496. DOI: 10.14744/SEMB.2019.67299. 


\section{$1=\sqrt{202(2)}$}

international Journal https://ijma.journals.ekb.eg/ Print ISSN: 2636-4174 Online ISSN: 2682-3780

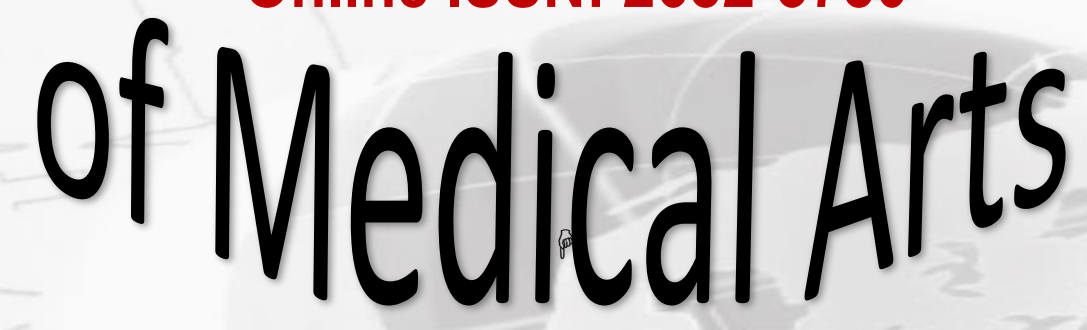

